\title{
Complete sets of mobile operation software for in-field calibration of electric energy meter
}

\author{
Jie Fan ${ }^{1,2, a}$, Xiao Chen ${ }^{1,2, b}$, Yongxian $\mathrm{Yi}^{1,2, \mathrm{c}}$, Yu Zhou ${ }^{1,2, \mathrm{c}}$ and Wei Xie ${ }^{3, \mathrm{~d}}$ \\ 1 Jiangsu Electric Power Company Research Institute. Nanjing 211103, China \\ 2 State Grid Key Laboratory of Electric Power Metrology, Nanjing 211103, China \\ 3 Jiangsu Frontier Electric Technology Co.,LTD, Nanjing 211103, China \\ a fanjie125@163.com, ${ }^{b}$ cx_012003@163.com, c cnyyx@sina.com, d yunduanxw@126.com
}

Keywords: Complete sets of mobile operation software, the process of in-field standardized operation, multiple data intelligent diagnostic model, abnormal operating state

\begin{abstract}
The analysis and record of data for traditional in-field calibration of electric energy meter relies on artificial work ${ }^{[1]}$, which will easily lead to data error due to human factors and unable to realize standardization of calibration. The complete sets of mobile operation software for in-field calibration of electric energy meter is embedded the process of in-field standardized operation, which can standardize the in-field calibration of electric energy meter and realize automatic identification of wiring mode and calibration methods of electric energy meter. It establishes the multiple data intelligent diagnostic model based on information such as current cutoff 、 lose of phase 、 voltage-loss and severe three-phase unbalance. By analyzing and comparing with the user data of Power User Electric Energy Data Acquire System, the model can automatically identify and diagnose abnormal power consumption behavior like stealing electricity. It also establishes a model for distinguishing the abnormal operating state of electric energy meter, which can realize automatic distinction of abnormal operating state of electric energy meter.
\end{abstract}

\section{Introduction}

Electric energy meter is a metrology apparatus for commercial exchange between electric power enterprises and customers, and calibration of electric energy meter is the duty of electric power marketing management ${ }^{[2]}$, which is very important to electric safety and power management. For a long time, the calibration personnel took the calibration instrument to the scene of the electric meter calibration, recorded the calibration data in the notebook, analyzed and screened the calibration data artificially, and then went back to the office to put the calibration data into the computer. The in-field calibration and background jobs in the office was performed separately, which cannot realize standardization of calibration and high-efficient work and analyzing and screening the calibration data artificially can easily lead to the data error of calibration.

The complete sets of mobile operation software for in-field calibration of electric energy meter is embedded the process of in-field standardized operation, which can standardize the in-field calibration of electric energy meter. It also uses a variety of encryption technology to access intranet system securely, realizing a seamless connection with the Marketing Information System. The software employs an intelligent recognition and matching technology of calibration methods and establishes database of calibration methods of electric power meter to realize automatic identification of wiring mode and calibration methods of electric energy meter. It establishes the multiple data intelligent diagnostic model based on information such as current cutoff 、 lose of phase 、 voltage-loss and severe three-phase unbalance. By analyzing and comparing with the user data of Power User Electric Energy Data Acquire System, the model can automatically identify and diagnose abnormal power consumption behavior like stealing electricity. It also establishes a model for distinguishing the abnormal operating state of electric energy meter, which can realize automatic distinction of abnormal operating state of electric energy meter. 


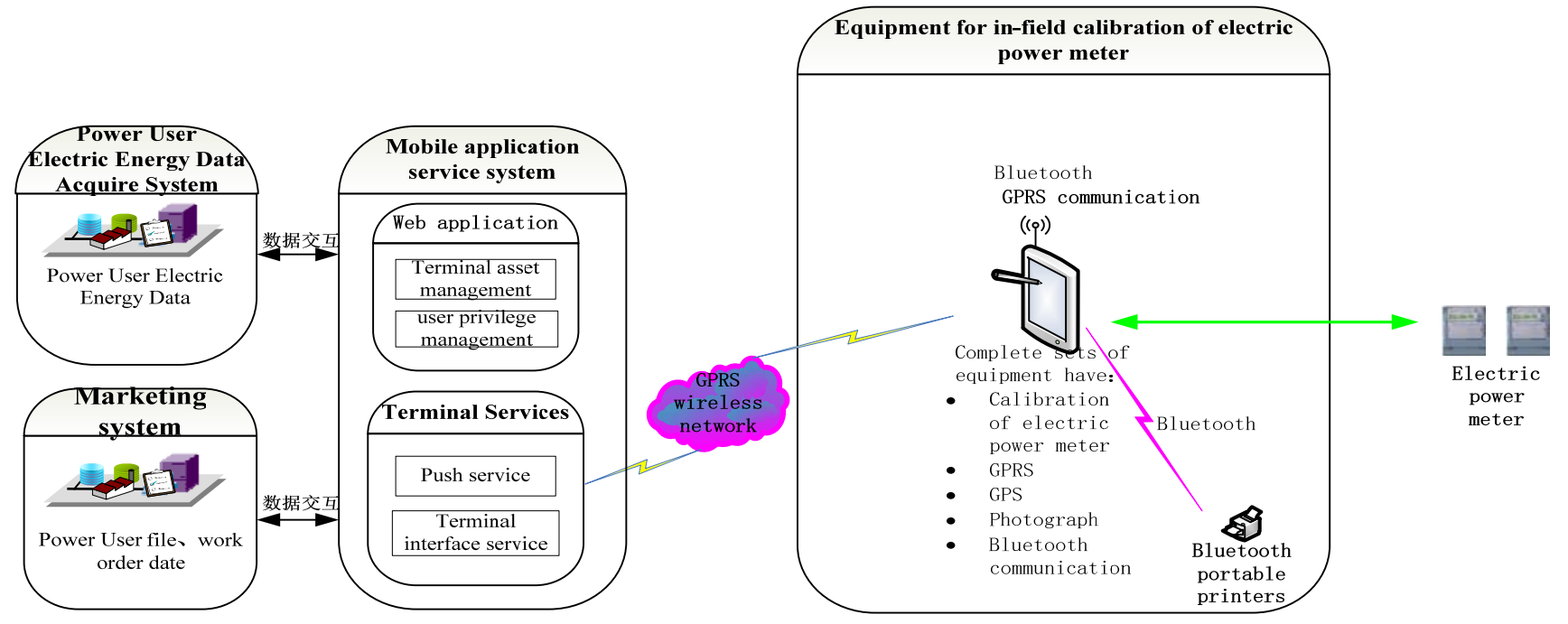

Fig.1. system architecture diagram

Mobile operation process for in-field calibration of Three-phase electric energy meter

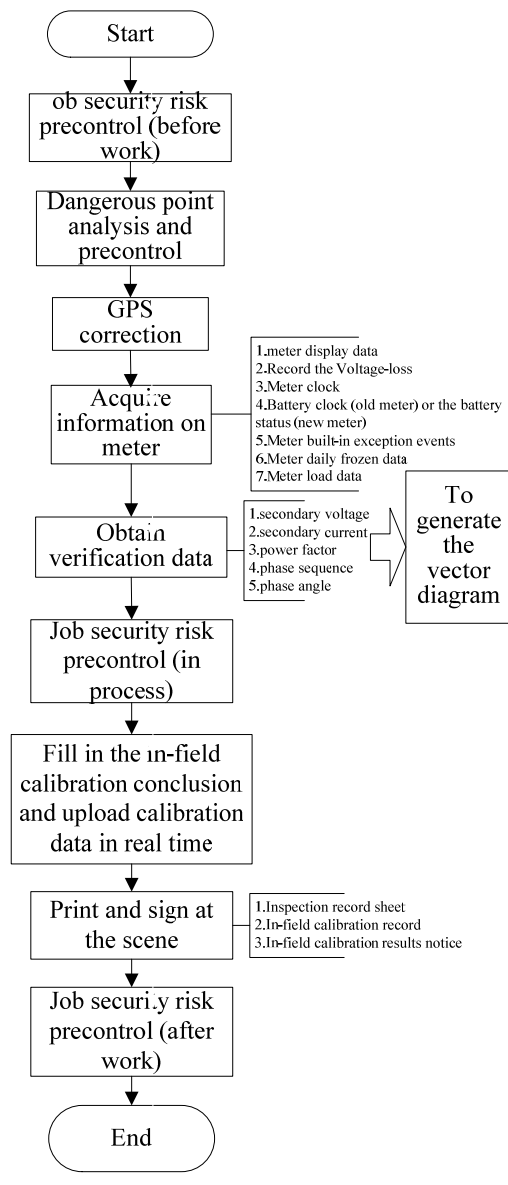

Mobile operation process for in-field calibration of single-phase electric energy meter

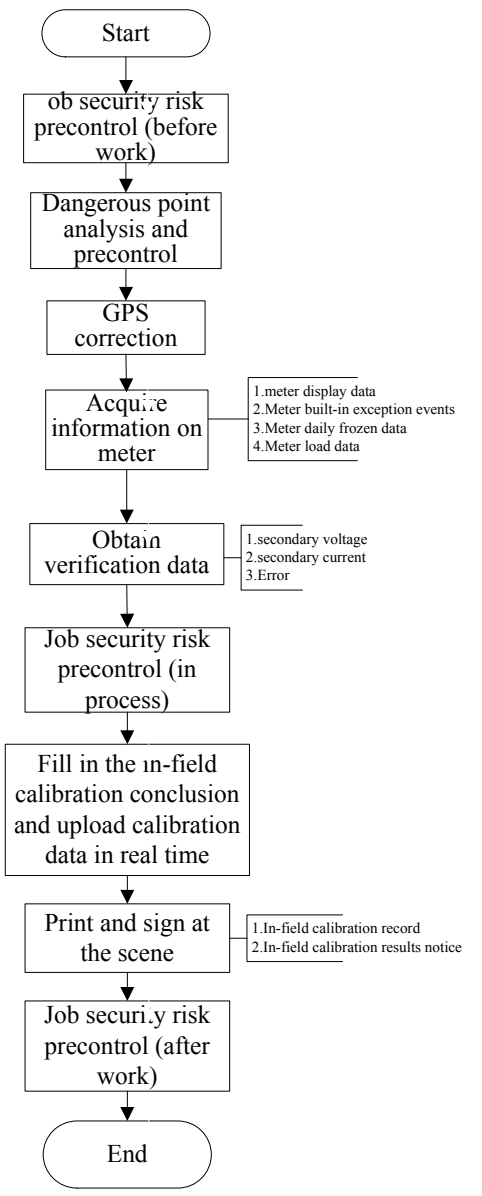

Fig.2. mobile operation standardization process for three-phase meter and single-phase meters

\section{Complete sets of mobile operation software for in-field calibration of electric energy meter}

The complete sets of mobile operation software for in-field calibration of electric energy meter is composed of the mobile application service system, network security access system, mobile communication network and complete sets of equipment for mobile operation. It is an important part of the Marketing Technical Supporting System. When implementing the in-field calibration of electric power meter, the intelligent mobile equipment is used to carry out automatic identification of 
calibration methods, in-field calibration, anomaly discrimination and data upload. It extends the existing in-field calibration of electric power meter from PC terminal to the intelligent handheld device, which makes it possible to connect the Marketing System in the scene of calibration. The system architecture diagram is shown in Fig.1.

\section{Standards and processes for in-filed calibration of electric power meter based on mobile operation}

Presently the cycle test of various grades of large users, the in-field calibration application of power user and other business process in the electric marketing businesses is operated in the traditional mode, namely the on-site inspection and marketing system separating operation mode, which is without mobile operation standardization process for in-field calibration of electric energy meter. Based on the existing electric energy meter calibration process and marketing system business process, this paper formulates the mobile operation standardization process for in-field calibration of electric energy meter of users of different voltage levels by using The principle of optimal hierarchical modeling and optimal strategy to realize standardized operation of in-field calibration, which includes processes for three-phase meter and single-phase meters as shown in Fig. $2^{[3][4]}$.

\section{Intelligent analysis technology of electric power meter state and abnormal operation}

According to the in-field calibration data, electric power meter data obtained at the scene, power user file from the Marketing System and Energy Data data acquisition system ${ }^{[5]}$, marketing system, watt-hour meter power data and combining with related analytical method, this paper propose intelligent analysis technology to analyze electric power meter state and abnormal operation. ${ }^{[6]}$

Calibration of electric power meter grade

(1) accuracy grade of electric power meter

$$
\frac{1}{n} \sum_{i=1}^{n} e_{i} \geq E \%
$$

Where $\mathrm{E}$ is the electric power meter grade, ei is the electric power meter error. If formula(1) meets, the electric power meter does not meet the level requirements. Else execute (2).

(2) trending early-warning

Get three values of accuracy grade of electric power meter recorded before, Combined with the value measured this time, a straight line forms as $\mathrm{S}=\mathrm{kT}+\mathrm{a}$ can be reached by curve fitting with the four points recorded $\left(\mathrm{T}_{\mathrm{i}}, \mathrm{S}_{\mathrm{i}}\right)(\mathrm{i}=1,2, \ldots 4)$.

If $\mathrm{k}>0$, Warning "attention please, electric power meter accuracy grade showed a decreasing tendency"

Basic analysis method of lose of phase v current cutoff 、voltage-loss and severe three-phase unbalance

Suggest $\mathrm{K}=10 \%$, in The following description, $\mathrm{U}_{\mathrm{n}}$ is nominal voltage, $\mathrm{I}_{\mathrm{n}}$ is nominal current, $\mathrm{I}_{\max }$ is the maximum current, $\mathrm{U}_{\mathrm{a}} 、 \mathrm{U}_{\mathrm{b}} 、 \mathrm{U}_{\mathrm{c}}$ is the three phases voltage measured at the scene. $\mathrm{I}_{\mathrm{a}} 、 \mathrm{I}_{\mathrm{b}} 、 \mathrm{I}_{\mathrm{c}}$ is the three phases current measured at the scene. When it is three-phase three-wire system, $\mathrm{U}_{\mathrm{a}}=\mathrm{U}_{\mathrm{ab}}$, $\mathrm{U}_{\mathrm{c}}=\mathrm{U}_{\mathrm{cb}}$.

(1) lose of phase

three-phase three-wire system: $\mathrm{U}_{\mathrm{a}}<K 1 \times \mathrm{U}_{\mathrm{n}}, \mathrm{I}_{\mathrm{a}}<K 2 \times \mathrm{I}_{\max }$ or $\mathrm{U}_{\mathrm{c}}<K 1 \times \mathrm{U}_{\mathrm{n}}, \mathrm{I}_{\mathrm{c}}<K 2 \times \mathrm{I}_{\max }$.

three-phase four-wire system: $\mathrm{U}_{\mathrm{a}}<K 1 \times \mathrm{U}_{\mathrm{n}}, \mathrm{I}_{\mathrm{a}}<K 2 \times \mathrm{I}_{\max }$ or $\mathrm{U}_{\mathrm{b}}<\mathrm{K} 1 \times \mathrm{U}_{\mathrm{n}}, \mathrm{I}_{\mathrm{b}}<\mathrm{K} 2 \times \mathrm{I}_{\max }$ or $\mathrm{U}_{\mathrm{c}}<K 1 \times \mathrm{U}_{\mathrm{n}}, \mathrm{I}_{\mathrm{c}}<K 2 \times \mathrm{I}_{\max }$.

suggest $\mathrm{K} 1=60 \%, \quad \mathrm{~K} 2=0.5 \%$.

(2) voltage-loss

three-phase three-wire system: $\mathrm{U}_{\mathrm{a}}<K 1 \times \mathrm{U}_{\mathrm{n}}, \mathrm{U}_{\mathrm{c}} \geq \mathrm{K} 2 \times \mathrm{U}_{\mathrm{n}}$ or $\mathrm{U}_{\mathrm{c}}<K 1 \times \mathrm{U}_{\mathrm{n}}, \mathrm{U}_{\mathrm{a}} \geq K 2 \times \mathrm{U}_{\mathrm{n}}$ 。 three-phase four-wire system: $\mathrm{U}_{\mathrm{a}}<K 1 \times \mathrm{U}_{\mathrm{n}}, \mathrm{U}_{\mathrm{b}} \geq \mathrm{K} 2 \times \mathrm{U}_{\mathrm{n}} \mid \mathrm{U}_{\mathrm{c}} \geq \mathrm{K} 2 \times \mathrm{U}_{\mathrm{n}}$ or $\mathrm{U}_{\mathrm{b}}<K 1 \times \mathrm{U}_{\mathrm{n}}$, $\mathrm{U}_{\mathrm{c}} \geq \mathrm{K} 2 \times \mathrm{U}_{\mathrm{n}} \mid \mathrm{U}_{\mathrm{a}} \geq \mathrm{K} 2 \times \mathrm{U}_{\mathrm{n}}$ or $\mathrm{U}_{\mathrm{c}}<K 1 \times \mathrm{U}_{\mathrm{n}}, \mathrm{U}_{\mathrm{a}} \geq \mathrm{K} 2 \times \mathrm{U}_{\mathrm{n}} \mid \mathrm{U}_{\mathrm{b}} \geq \mathrm{K} 2 \times \mathrm{U}_{\mathrm{n}}$.

suggest $K 1=15 \%$ ，K2 $=60 \%$ 。 
(3) undervoltage

three-phase three-wire system: $\mathrm{U}_{\mathrm{a}}<K 1 \times \mathrm{U}_{\mathrm{n}}$ 或 $\mathrm{U}_{\mathrm{c}}<K 1 \times \mathrm{U}_{\mathrm{n}}$

three-phase four-wire system: $\mathrm{U}_{\mathrm{a}}<K 1 \times \mathrm{U}_{\mathrm{n}}$ or $\mathrm{U}_{\mathrm{b}}<K 1 \times \mathrm{U}_{\mathrm{n}}$ or $\mathrm{U}_{\mathrm{c}}<K 1 \times \mathrm{U}_{\mathrm{n}}$ 。

suggest $\mathrm{K} 1=15 \%$ 。

(4) current cutoff

Exclude these areas: area circuit loss $<10 \%$.

three-phase three-wire system: $\mathrm{I}_{\mathrm{a}}<K 1 \times \mathrm{I}_{\mathrm{n}}, \mathrm{I}_{\mathrm{c}} \geq \mathrm{K} 2 \times \mathrm{I}_{\mathrm{n}}$ or $\mathrm{I}_{\mathrm{c}}<K 1 \times \mathrm{I}_{\mathrm{n}}, \mathrm{I}_{\mathrm{a}} \geq \mathrm{K} 2 \times \mathrm{I}_{\mathrm{n}}$ 。

three-phase four-wire system: $\mathrm{I}_{\mathrm{a}}<K 1 \times \mathrm{I}_{\mathrm{n}}, \quad \mathrm{I}_{\mathrm{b}} \geq \mathrm{K} 3 \times \mathrm{I}_{\mathrm{n}} \mid \mathrm{I}_{\mathrm{c}} \geq \mathrm{K} 3 \times \mathrm{I}_{\mathrm{n}}$ or $\mathrm{I}_{\mathrm{b}}<K 1 \times \mathrm{I}_{\mathrm{n}}$, $\mathrm{I}_{\mathrm{a}} \geq \mathrm{K} 3 \times \mathrm{I}_{\mathrm{n}} \mid \mathrm{I}_{\mathrm{c}} \geq \mathrm{K} 3 \times \mathrm{I}_{\mathrm{n}}$ or $\mathrm{I}_{\mathrm{c}}<K 1 \times \mathrm{I}_{\mathrm{n}}, \mathrm{I}_{\mathrm{a}} \geq \mathrm{K} 3 \times \mathrm{I}_{\mathrm{n}} \mid \mathrm{I}_{\mathrm{b}} \geq \mathrm{K} 3 \times \mathrm{I}_{\mathrm{n}}$.

suggest $\mathrm{K} 1=1 \%, \mathrm{~K} 2=5 \%, \mathrm{~K} 3=10 \%$.

(5) three-phase current unbalance

$\frac{\operatorname{Max}\left(\mathrm{I}_{\mathrm{a}}, \mathrm{I}_{\mathrm{b}}, \mathrm{I}_{\mathrm{c}}\right)-\operatorname{Min}\left(\mathrm{I}_{\mathrm{a}}, \mathrm{I}_{\mathrm{b}}, \mathrm{I}_{\mathrm{c}}\right)}{\operatorname{Max}\left(\mathrm{I}_{\mathrm{a}}, \mathrm{I}_{\mathrm{b}}, \mathrm{I}_{\mathrm{c}}\right)}>K$
suggest $\mathrm{K}=30 \%$.

(6) overcurrent

$\mathrm{I}_{\mathrm{a}}>K \times \mathrm{I}_{\max }$ or $\mathrm{I}_{\mathrm{b}}>K \times \mathrm{I}_{\max }$ or $\mathrm{I}_{\mathrm{c}}>K \times \mathrm{I}_{\max }$

\section{Analysis method of abnormally operating state of electric power meter}

(1) backward counting of electric power meter

Data sources: Meter daily frozen positive /negative active total electrical power indicating value, positive (combination) reactive total electrical power indicating value, real-time forward/reverse active total electrical power indicating value and positive (combination) of total electrical power indicating value read at the scene

Definition: The meter reading data decreases compared with the last data.

Diagnose method: Daily positive /negative active total electrical power indicating value and positive (combination) reactive total electrical power indicating value are less than the values of last day.

Formula: $W-W_{1}<0$, where $W$ is the latest electrical power indicating value, $W_{1}$ is the last day electrical power indicating value.

(2) stop counting of electric power meter

Data sources: Meter daily frozen positive /negative active total electrical power indicating value, and real-time forward/reverse active total electrical power indicating value read at the scene.

Definition: The meter stops counting when the user is consuming the electric power.

Diagnose method: The difference between daily positive /negative active total electrical power indicating values in two days equals zero and three phase current values are bigger than $0.1 \mathrm{~A}$.

Formula: $W-W_{1}=0$, where $W$ is the latest electrical power indicating value, $W_{1}$ is the last day electrical power indicating value, and $\left(\mathrm{I}_{\mathrm{a}}>0.1\left|\mathrm{I}_{\mathrm{b}}>0.1\right| \mathrm{I}_{\mathrm{c}}>0.1\right)$ is true.

(3) fast counting of electric power meter

Data sources: Meter daily frozen positive /negative active total electrical power indicating value, and real-time forward/reverse active total electrical power indicating value read at the scene.

Definition: The daily electric power data of meter is significantly larger than the normal value.

Diagnose method: The ratio of the daily electric power data of meter and the possible daily maximum power consumption value is larger than threshold value $\mathrm{K}$.

Formula: $\frac{\text { daily electric power data }}{\text { possible daily maximum power consumption value }}>K$, where the possible daily maximum power consumption value can be calculate as $\mathrm{I}_{\max } \times \mathrm{U}_{\mathrm{n}} \times 24 \mathrm{~h}$. The suggested value of $\mathrm{K}$ is 3 .

(4) Inequality of electric power meter indicating value

Data sources: Meter daily frozen positive /negative active total electrical power indicating data block read at the scene.

Definition: The total electrical power indicating value is not equal to the sum of indicating value of all electric rates.

Formula: $W_{\text {total }} \neq W_{\text {tip }}+W_{\text {peak }}+W_{\text {flat }}+W_{\text {valley }}$ 
(5) Clock abnormity of electric power meter

Data sources: Calendar clock of electric power meter read at the scene.

Definition: Clock error of electric power meter out of tolerance.

Diagnose method: The absolute value of the difference between standard time and the calendar clock of electric power meter is larger than the threshold value $\mathrm{K}$.

Formula: $\left|\left(T_{s}-T_{m}\right)\right| \geq K$ 。 where $T s$ is the standard time and Tm is the calendar clock of electric power meter.

The suggested value of $\mathrm{K}$ is $0 \sim 1 \mathrm{~min}, 1 \sim 5 \mathrm{~min}$ and $5 \sim 15 \mathrm{~min}$.

(6) Reverse power abnormity

Data sources: Meter daily frozen positive /negative active total electrical power indicating data block read at the scene.

Definition: The electric power meters of normal electricity users appear reverse power.

Diagnose method: Reverse active total electrical power indicating value is larger than 0 and the reverse power value of the latest day is larger than the threshold value $K$, the suggested value of $K$ is $1 \mathrm{kWh}$.

(7) B phase abnormality of high voltage power supply and high voltage side metering users

Data sources: B phase voltage and B phase current read at the scene.

Definition: When the metering model is high voltage power supply and high voltage side metering, the B phase voltage or current of the three-phase three-wire system is not zero, namely $\left|\mathrm{I}_{\mathrm{b}}\right|>0$ or $\left|\mathrm{U}_{\mathrm{b}}\right|>0$.

(8) Demand surpasses capacity

Data sources: The maximum demand of electric power meter read at the scene.

Definition: The maximum demand surpasses the user's contract capacity.

Diagnose method: Judge whether the demand of electric power meter surpasses the contract capacity of user by calculating the ratio of demand and capacity and compare it with the threshold value $\mathrm{K}$, namely $\frac{\text { MaximumdemandxCTXPT }}{\text { contract capacty }}>\mathrm{K}$.

3 levels of $\mathrm{K}$ value is suggested, the default 3 values of $\mathrm{K}$ is $80 \%, 110 \%$ and $130 \%$.

\section{Summary}

The complete sets of mobile operation software for in-field calibration of electric energy meter realize the standardized operation of electric power meter calibration, standardizes the in-field calibration of electric power meter. It uses a variety of encryption technology to realize a seamless connection with the Marketing Information System. By proposing the intelligent analysis technology of electric power meter state and abnormal operation, the software realizes intelligent analysis of in-field calibration data and automatic identification of state and abnormal operation of electric power meter, which improves the accuracy rate of in-field data, improves the working efficiency, effectively enhances the efficiency of business management and the service quality.

\section{References}

[1] YAO Li,LI Shao-teng,LU Chun-guang: Design of Detection Equipment for Digital Electrical Energy Meters, Electrical Measurement \& Instrumentation (2010)

[2] RUAN Chun-Lei,YAO Ming-Hai,HUANG Lei: Power Meter Detection System Based on Computer Vision, Computer Systems \& Applications (2013)

[3] IEC61850-9-1, Communication networks and systems in substations-Specific communication service mapping (SCSM)- Sampled values over serial unidirectional multidrop point to point link[S]. [4] IEC61850-9-2, Communication networks and systems in substations-Specific communication service mapping (SCSM)- Sampled values over ISO/IEC 8802-3[S].

[5] IEC61850 -9-2LE, Implementation guideline for digital interface to instrument transformers using [S].

[6] IEC60044-8, Instrument transformers- Part8: Electronic current transformers [S]. 